\title{
Network analysis
}

\section{Kristine Maciejewski ${ }^{1}$ and Jacopo Baggio ${ }^{2,3}$}

\author{
${ }^{1}$ CENTRE FOR SUSTAINABILITY TRANSITIONS, STELLENBOSCH UNIVERSITY, STELLENBOSCH, SOUTH AFRICA \\ ${ }^{2}$ SCHOOL OF POLITICS, SECURITY, AND INTERNATIONAL AFFAIRS, UNIVERSITY OF CENTRAL FLORIDA, FLORIDA, USA \\ ${ }^{3}$ SUSTAINABLE COASTAL SYSTEMS CLUSTER, NATIONAL CENTER FOR INTEGRATED COASTAL RESEARCH, \\ UNIVERSITY OF CENTRAL FLORIDA, FLORIDA, USA
}

\section{Key methods discussed in this chapter}

Network analysis

\section{Connections to other chapters}

Network analysis connects to various other methods, particularly as it relies on the collection of data which is covered in ecological field data collection (Chapter 6), interviews and surveys (Chapter 7) and participatory data collection (Chapter 8). The metrics generated through network analysis can be statistically analysed and therefore linked to statistical analysis (Chapter 18). As a tool, network analysis can also be linked to ecosystem service modelling (Chapter 31) to study the linkages between social and ecological components in a system.

\section{Introduction}

Network analysis, based on graph theory and statistics, provides a rigorous, systematic approach to studying how relationships and their structuring influence social-ecological systems (SES). A network perspective allows a researcher to analyse how landscape, species, individuals and organisations, among others, are connected and how these structures enable specific processes such as information sharing, opinions, policy adoption, species migration, the spread of epidemics and ecosystem flows (Dakos et al. 2015). Network analysis is widely used to analyse the structural properties of complex systems and gives insight into how a system works by understanding the role that individual parts play in the system through their connections to other parts. This method frees us from the typical assumptions that individuals act independently. Instead, it embraces the importance of relationships and provides a potential bridge between different disciplines.

Generally speaking, a network is defined as a set of nodes connected via edges. That is, a network consists of two types of components: (a) nodes (also called 'vertices' or 'actors'), which can represent people, places, organisations, species and so on, and (b) edges (ties, 


\begin{tabular}{|c|c|}
\hline DISCIPLINARY BACKGROUND & KNOWLEDGE TYPE \\
\hline $\begin{array}{l}\text { The methods in this chapter are derived } \\
\text { from or have most commonly been used in: } \\
\text { Ecology, Resource Economics, } \\
\text { Computational Geography, Systems } \\
\text { Dynamics, Computer Science, } \\
\text { Information Science }\end{array}$ & $\begin{array}{l}\text { The methods in this chapter are primarily } \\
\text { used to generate the following types of } \\
\text { knowledge: } \\
\text { - Descriptive } \\
\text { - Exploratory } \\
\text { - Explanatory }\end{array}$ \\
\hline RESEARCH APPROACH & PURPOSE OF METHOD \\
\hline $\begin{array}{l}\text { The methods in this chapter originate } \\
\text { from or most commonly adopt the } \\
\text { following research approaches: } \\
\text { - Analytical/objective }\end{array}$ & $\begin{array}{l}\text { The most common purposes of using the } \\
\text { methods in this chapter are: } \\
\text { - System understanding }\end{array}$ \\
\hline TEMPORAL DIMENSION & SYSTEMIC FEATURES AND PROCESSES \\
\hline $\begin{array}{l}\text { The methods in this chapter are most } \\
\text { commonly applied to the following } \\
\text { temporal dimensions: } \\
\text { - Present (typically within the last } \\
5-10 \text { years) } \\
\text { - Recent past (post-1700s) }\end{array}$ & \multirow{3}{*}{$\begin{array}{l}\text { While most methods can do many } \\
\text { things, the methods in this chapter are } \\
\text { particularly good (i.e. go-to methods) for } \\
\text { addressing the following: } \\
\text { - SES components and linkages } \\
\text { - Power relations } \\
\text { - Collective action and collaborative } \\
\text { governance }\end{array}$} \\
\hline SPATIAL DIMENSION & \\
\hline $\begin{array}{l}\text { The methods in this chapter are primarily } \\
\text { either or both: } \\
\text { - Non-spatial } \\
\text { The methods in this chapter are most } \\
\text { commonly applied at the following } \\
\text { spatial scales: } \\
\text { - Local } \\
\text { - Regional (provincial/state } \\
\text { to continental) }\end{array}$ & \\
\hline
\end{tabular}


relationships, links), which represent a 'connection' existing between two nodes. Edges can represent friendships, legal authorities, collaborations, conflicts and also species migration, ecosystem flows, resource exchanges (including predation) and extraction. Networks can either be directed or undirected, and weighted or unweighted. Directed networks often represent a flow of information, e.g. from A to B but not vice versa, whereas undirected networks represent an interaction between two nodes (A and B) but with no direction. Edges can be unweighted, representing only instances in which $\mathrm{A}$ and $\mathrm{B}$ are connected or not; or weighted, representing also the 'strength' of the connection between A and B. Weights can be based on distance, frequency of contact, amount of resources exchanged, or 'value judgement of the relationship'.

The first study of networks can be ascribed to Euler in 1739 when he abstracted a geographical space and for the first time described entities as nodes and edges, representing land and bridges connecting different parts of Königsberg in Germany (Euler and Euler 1736). Two centuries later, modern network analysis originated from the social sciences. Jacob L. Moreno, an American psychiatrist, was interested in the dynamics of social interactions and used network analysis to map a social network of Hudson School for Girls, following an epidemic of runaway children in 1932 (Borgatti et al. 2009). He graphically mapped individuals' feelings towards one another to identify the channels of social influence and ideas among the girls. In the 1940s and 1950s, work in social network mapping or analyses advanced towards the use of matrix algebra and graph theory as researchers began to study the effects of different communication network structures to solve problems (Moreno 1934).

About 20 years later, another step towards modern network analysis was undertaken by two Hungarian mathematicians, Paul Erdös and Alfréd Rényi, who mathematically described the properties of random graphs (Erdös and Rényi 1959, 1960). However, it was not until the end of the 1990s and the beginning of the 2000s, with the advancement of computing power to analyse data, that network analysis really took off as a method to assess the structural properties of complex systems (Watts and Strogatz 1998; Albert and Barabási 2001). The use of network analysis enabled researchers to start disentangling the relationships between human and organisational interactions and how structure facilitates specific outcomes, such as the ranking of economists and understanding psychological well-being. It was also used in social and policy analysis. Today, network analysis is used in a wide variety of different fields including neuroscience, economics, political science, genetics, ecology, biology, sociology, psychology, engineering, computer science and physics (Caldarelli 2007; Borgatti et al. 2009; Barthélemy 2011; Costa et al. 2011).

Although network analysis has a long interdisciplinary history, its application to SES (involving the construction specifically of interlinked social-ecological networks) has started only recently (Bodin and Tengö 2012; Baggio et al. 2016; Bodin et al. 2016; Barnes et al. 2017; Sayles and Baggio 2017a; Baggio and Hillis 2018; Sayles et al. 2019). Network analysis can be used to analyse and assess how social and ecological processes are influenced by the underlying connectivity structure.

This chapter focuses on applications of network analysis to SES. Network analysis can be used in combination with other methods in this handbook, such as interviews and surveys (Chapter 7) and ecological field data collection (Chapter 6) to better understand SES.

\section{SES problems and questions}

In the context of SES, network analysis can be used to understand how social and ecological system components are connected and how the structure or pattern of connections affects the function of the SES, thus taking account of how systems are constituted relationally. 
Ecological and social processes 'propagate' along specific networks and connectivity. Network structure plays a central role in constraining and/or facilitating these different processes. Examples of key social processes (flows) in SES include sharing ideas, management strategies, information, knowledge, economic/financial flows, and conflict and cooperation. Examples of key ecological processes (flows) in SES include nutrient flows, the transfer of energy from one species to another (food webs), water flowing within rivers and species migration. These social and ecological processes are connected via specific processes related to management (e.g. altering specific social and/or ecological processes such as creating forums for sharing ideas on natural resource management, damming a river, building fences), resource extraction (e.g. water, food, hunting) and resource production (e.g. pollution). These processes are often interdependent and interact with one another.

Both local and global network characteristics affect how specific social-ecological processes unfold. In fact, specific 'structures' (values of metrics, distribution of nodal metrics) can facilitate or hinder species migration, the spread of pests, biological invasion, knowledge sharing, management strategies, innovations, learning, financial flows and food sharing (Garlaschelli 2004; Bodin and Norberg 2007; Baggio et al. 2011; Barthélemy 2011; Costa et al. 2011; Granell, Gomez, and Arenas 2014; De Domenico et al. 2016). More so, network analysis can show how structural characteristics of SES can affect their ability of a system to withstand specific disturbances, and can give insight into how processes and flows may change in response to those disturbances (Albert, Jeong, and Barabási 2000; Nicosia et al. 2012; De Domenico et al. 2014; Brummitt, Barnett, and D’Souza 2015; Poledna et al. 2015; Baggio et al. 2016).

Typical questions that network analysis can be used for to understand SES include:

- Who are the key stakeholders, potential leaders or agents of change in the system? (e.g. a study by Bodin and Crona (2008) used network analysis to identify key individuals in a fishing community to explain the lack of common initiative to deal with the overexploitation of fisheries)

- Which specific human-environmental dependencies are key for the functioning of the overall system? (e.g. network analysis was used to link processes of change in SES to decision-making across multiple layers of rules underpinning societal organisation (Barnes et al. 2017))

- Are there spatial-scale mismatches between social and ecological systems within an SES? (e.g. are there issues of fit between ecological processes to be managed and the sociopolitical unit tasks involved in managing these systems? (Sayles and Baggio 2017b))

- How do individuals affect ecological processes? (e.g. a wildfire transmission network, developed through simulation of wildfires, was compared to a governance network to determine 'risk interdependence archetypes' based on the spatial configurations by which one actor is exposed to risk through the actions of another actor (Hamilton, Fischer, and Ager 2019))

- How can social perceptions of an SES be assessed? (e.g. using data collected from participatory workshops, network analysis was used to map out how communities perceive the performance of a community-based natural resource management system (Delgado-Serrano et al. 2015))

- How do systems respond to exogenous effects? (e.g. Frank and Fahrbach (1999) studied the interactions between actors and their sentiments (values, attitudes, beliefs, opinions) to understand how natural resource use is influenced by others)

- How do collaborations emerge and function within the context of natural resource management? (e.g. Bodin et al. (2017) used network analysis to show that different network characteristics can give rise to similar ecosystem-based management outcomes) 
- How is collaboration influenced by the origin of the relationship? (e.g. Sayles and Baggio (2017b) looked at the difference in perceived collaboration productivity between relationships that were mandated, born out of shared interest, funded, or a mix of the three categories)

Network analysis may also be used to facilitate collaborative processes for scoping the nature of the relationships that shape SES and interactions (e.g. using NET-MAP, an interview-based mapping tool that helps people to understand, visualise, discuss and improve situations in which many different actors influence outcomes (netmap.wordpress.com/about) in order to map stakeholder networks in facilitated processes aimed at the co-production of knowledge related to a specific SES).

\section{Brief description of key methods}

Network analysis can be used to understand how entities (social and/or ecological structures) are connected and how they relate to one another. In network analysis, these properties can be quantified using network metrics that have been developed to answer specific questions.

By calculating the centrality value of a network, one can determine the most central node in the network, which can be seen as the most important node that connects all the nodes. An outbreak or spread of a virus in a population, for example, can be illustrated using network analysis, where the nodes represent the infected individuals and the interaction between individuals, and the transmission or spread of the virus is depicted as the edges of the network. The individuals' position in the population can be described by calculating the centrality value of each node in the network using centrality analysis (Table 23.1). The most central node represents the individual with the highest number of contacts. This information can then be used to identify the most contagious individual in the network, or where the virus originally started from.

As shown in Table 23.1, network analysis can be used to understand species interactions in food webs by simulating species loss. For each food web, species can be sequentially removed, focusing on the most connected species, randomly chosen species and the least connected species. The number of prey and predator links can then be counted to determine total trophic connections, or network degree. This can also be used to determine the robustness of food webs, as the fraction of species that had to be removed to result in a total loss of less than $50 \%$ of the species (Dunne, Williams, and Martinez 2002). Network analysis can also be used to track species movement patterns across habitat patches to quantify habitat connectivity. This is particularly relevant for managing conservation landscapes as it helps to identify critical 'stepping stone' patches that, when removed, may cause changes in habitat connectivity (Keitt, Urban, and Milne 1997).

Table 23.1 summarises a few of the most common uses of network analysis metrics in SES research.

\section{Limitations}

As SES are characterised by dynamic interactions between many social and/or ecological components, it is challenging to capture all the relevant actors and social and ecological relationships. Social-ecological systems are also 'open' systems that have interactions with other systems, and are therefore not clearly bounded. The structure of the network depends on the context of the system, which is usually clarified by setting system boundaries. The choice of boundary therefore has direct implications. 
Table 23.1 Summary of key metrics used in network analysis

\begin{tabular}{|c|c|c|}
\hline Main application & Description & References \\
\hline Centrality analysis & $\begin{array}{l}\text { Centrality analysis is used to identify the } \\
\text { role of key individuals to enable natural } \\
\text { resource governance, and/or species/ } \\
\text { landscape patches that are key to the } \\
\text { stability of an ecosystem. }\end{array}$ & Bodin and Crona 2008 \\
\hline $\begin{array}{l}\text { Centrality/ } \\
\text { participation } \\
\text { coefficient analysis } \\
\text { mixing network and } \\
\text { 'reason for existing } \\
\text { relationship' }\end{array}$ & $\begin{array}{l}\text { Centrality/participation coefficient analysis } \\
\text { is used to identify how different types of } \\
\text { relationships may affect productivity and/or } \\
\text { outcomes in SES. }\end{array}$ & Sayles and Baggio 2017b \\
\hline $\begin{array}{l}\text { Mono or multiplex } \\
\text { network analysis of } \\
\text { 'sharing' relationship }\end{array}$ & $\begin{array}{l}\text { Understanding the perceptions of local } \\
\text { communities and sharing relationships } \\
\text { may assist in building resilience in } \\
\text { community-based natural resource } \\
\text { management. }\end{array}$ & $\begin{array}{l}\text { Delgado-Serrano et al. 2015; } \\
\text { Baggio et al. } 2016\end{array}$ \\
\hline $\begin{array}{l}\text { Modelling motifs of } \\
\text { social-ecological } \\
\text { networks }\end{array}$ & $\begin{array}{l}\text { Modelling motifs of social-ecological } \\
\text { networks help researchers to understand } \\
\text { how natural resource users make decisions } \\
\text { and how these decisions are influenced by } \\
\text { different types of relationships. }\end{array}$ & $\begin{array}{l}\text { Frank and Fahrbach } 1999 ; \\
\text { Bodin et al. } 2016 ; \\
\text { Barnes et al. } 2017\end{array}$ \\
\hline Food web analysis & $\begin{array}{l}\text { Food web analysis is used to understand } \\
\text { species interactions and identify keystone } \\
\text { species. }\end{array}$ & $\begin{array}{l}\text { Dunne, Williams, and } \\
\text { Martinez 2002; } \\
\text { Garlaschelli 2004 }\end{array}$ \\
\hline $\begin{array}{l}\text { Map out species } \\
\text { movement patterns }\end{array}$ & $\begin{array}{l}\text { Animal movements between habitat } \\
\text { patches are used to map out the } \\
\text { movement patterns of species to identify } \\
\text { improved habitat connectivity. }\end{array}$ & $\begin{array}{l}\text { Keitt, Urban, and Milne 1997; } \\
\text { Urban and Keitt 2001; } \\
\text { Minor and Urban 2007; } \\
\text { Baggio et al. } 2011\end{array}$ \\
\hline $\begin{array}{l}\text { Map out and analyse } \\
\text { social-ecological } \\
\text { interactions }\end{array}$ & $\begin{array}{l}\text { By mapping out and analysing social- } \\
\text { ecological interactions, researchers } \\
\text { can understand how actors and their } \\
\text { relationship with other actors, and with } \\
\text { different interconnected ecosystem } \\
\text { components, contribute to different } \\
\text { management/governance outcomes. }\end{array}$ & $\begin{array}{l}\text { Bodin and Tengö 2012; } \\
\text { Sayles and Baggio 2017a }\end{array}$ \\
\hline $\begin{array}{l}\text { Model processes in } \\
\text { networks }\end{array}$ & $\begin{array}{l}\text { By modelling the processes in networks, } \\
\text { researchers can assess how structural } \\
\text { properties joined with specific nodal } \\
\text { characteristics influence ecological and } \\
\text { social flows. }\end{array}$ & Baggio and Hillis 2018 \\
\hline $\begin{array}{l}\text { Plot multi-level } \\
\text { networks }\end{array}$ & $\begin{array}{l}\text { Plotting multi-level networks enable } \\
\text { researchers to compare two or more } \\
\text { interconnected networks. }\end{array}$ & $\begin{array}{l}\text { Bodin and Tengö 2012; } \\
\text { Barnes et al. } 2017\end{array}$ \\
\hline
\end{tabular}


Since many network analysis methods demand complete network data (with all relevant links and nodes within the system boundaries being defined and measured), they are often limited to a particular and contextual scale, and therefore not always useful for capturing the radical openness of systems. Collecting the empirical data that underlie a network analysis often requires extensive fieldwork, which typically involves interacting with or surveying as many actors as possible. Network analysis therefore requires extensive effort in terms of both time and money for a network to be correctly inferred. In fact, given the specificity of network data, one cannot rely on random sampling but needs to rely on different sampling techniques (e.g. snowball, census).

Network analysis often represents merely a snapshot of how the system is connected. However, this limitation can be overcome by a dynamic network analysis, which is particularly useful for assessing causalities and answering questions such as what factors contribute to the formation of certain networks. Still, given time and cost constraints, as well as the potential fatigue of individuals in the case of social networks, longitudinal network studies are rare.

\section{Resource implications}

Network analysis software consists of either packages based on graphical user interfaces (GUIs) or packages built for scripting and coding. The GUI packages are generally easier to learn and are widely used. There are many open-source examples such as Gephi, NodeXL, EgoNet, MPnet and UCINet.

Scripting tools used for network analysis include NetMiner with a Python scripting engine; the statnet suite of packages for the R statistical programming language, igraph; the NetworkX library for Python; and the SNAP packages for network analysis in C++ and Python. Scripting tools can also be based in $\mathrm{R}$ via the sna, igraph and statnet packages. For advanced network analysis that relates to the use of ERGM, statnet in $\mathrm{R}$ and the stand-alone Pnet can be used. For multi-layer/multiplex network analysis in R, one can use the multinet package or MuxViz, which has its own interface. Multiplex networks can also be analysed in Python via the Pymnet package.

\section{New directions}

Although social-ecological network analysis (SENA) is still in its infancy, it has shown promise in advancing difficult SES problems such as identifying potential social-ecological scale mismatches (Sayles and Baggio 2017a) and assessing the robustness of social-ecological networks to social or ecological perturbations (Markowetz 2010). Looking towards the future, better integration of qualitative data-collection methods and protocols, with a strong and rigorous mathematical framework to analyse the complex web of interactions and interdependencies that exist in SES, is still needed.

Promising tools from a mathematical or statistical perspective are the implementation of multi-level exponential random graphs (Wang et al. 2009) and multi-layer/multiplex networks (De Domenico et al. 2014; Kivelä et al. 2014). Exponential random graphs (and by extension multi-level exponential random graphs) enable the analysis of SES via the presence of specific microlevel configurations called 'motifs' (Bodin and Tengö 2012; Bodin et al. 2016; Barnes et al. 2017; Guerrero et al. 2018). Exponential random graph motifs allow a researcher to understand how macrolevel structures are probabilistically related to specific network motifs, and how those motifs may affect outcomes of interest. Multi-layer networks allow researchers to analyse the overall macrolevel network properties and local nodal properties in multiple interdependent networks (Bodin et al. 2019). 


\section{Case study 23.1: Protected area networks in South Africa}

Protected area networks respectively situated in the Western and Eastern Cape provinces of South Africa illustrate how network analysis can be used to measure the resilience of SES and to identify individual actors that are important for overall network connectivity (Maciejewski and Cumming 2015).

Interviews were conducted with managers from various protected areas in the two protected area networks to understand how those managers were interacting with managers from surrounding protected areas. Interaction was defined as exchanging ideas; sharing equipment; trading in wildlife; engaging in discussions with regard to management, education, tourism and research; and forming collaborations, among others. This information was used to generate a graph network, where nodes represented the protected areas where interviewed managers were based (source) as well as the protected areas (targets) to which they were connected through various interactions. The edges (links) of the protected area network concerned consisted of directed linkages between source and target protected areas.

Network analysis indicated that the role of protected areas differed in management strategies between the two protected area networks, as illustrated by the positioning and size of the nodes and the density of connections (Figure 23.1). Nodes were sized according to each node's eigenvector (characteristic vector) centrality, which is a measure of the influence of a node in a network. A high eigenvector centrality score means a node is connected to many nodes which themselves have high scores, and indicate that they are in a position to receive and control flows (Borgatti 2005). Both protected area networks had shorter diameters than expected. This suggests frequent interactions between the managers, which may be beneficial to the spread of information (Janssen et al. 2006). A small network diameter also indicates high reachability, which increases the ability of the system to respond to change.

Both networks exhibited socio-economic interactions that were more intense between protected areas situated near one another in geographic space than between protected areas belonging to the same organisation. In other words, as would be expected for ecological connectivity, geographic proximity mattered more than organisational membership in the formation of socio-economic interactions.

The networks in Figure 23.1 were generated using network analysis. Nodes are coloured or shaded according to organisation (salmon/black: national parks; yellow/

\section{Key readings}

Barabási, A-L. n.d. Network Science. www.networksciencebook.com/chapter/1 (Online and free).

Bodin, Ö., and B. Crona. 2008. 'Community-Based Management of Natural Resources - Exploring the Role of Social Capital and Leadership in a Rural Fishing Community.' World Development 36(12): 2763-2779.

Bodin, Ö., and M. Tengö. 2012. 'Disentangling Intangible Social-Ecological Systems.' Global Environmental Change 22(2): 430-439. doi:10.1016/j.gloenvcha.2012.01.005.

Gonzalez, A., P. Thompson, and M. Loreau. 2017. 'Spatial Ecological Networks: Planning for Sustainability on the Long-term.' Current Opinion in Environmental Sustainability 29: 187-197.

Wasserman, S., and K. Faust. 1994. Social Network Analysis: Methods and Applications. Cambridge: Cambridge University Press. 
(A)

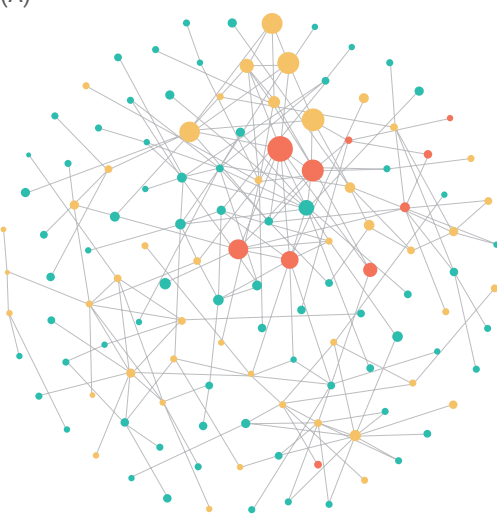

(B)

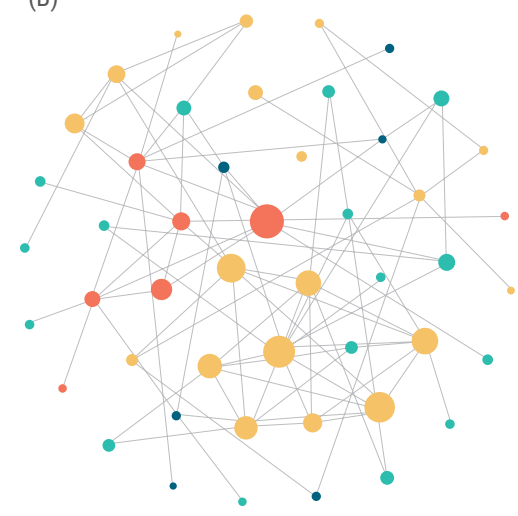

Figure 23.1 Protected area network of (A) the Western Cape, and (B) the Eastern Cape province of South Africa (Maciejewski and Cumming 2015)

dark grey: provincial parks; green/grey: private protected areas) and were sized and positioned according to centrality.

This example illustrates how network analysis provides a platform to spatially present the relational arrangement between SES components and how this can be used to understand the most important role-players in these networks, as well as those acting as stepping stones. Understanding the arrangement of different socio-economic interactions and the role that individual protected areas play in the network is important when it comes to making decisions about the network as a whole. In the Western Cape, for example, national parks should be consulted when designing the protected area expansion strategy or when making national overarching decisions about the future development of protected areas. However, when dealing with the management of private parks, it would be more strategic to consult with the surrounding provincial parks. This is clearly illustrated in the Biodiversity Stewardship Programme initiated by CapeNature in 2003, which facilitates conservation on privately owned land by setting up agreements between landowners and the provincial parks.

\section{References}

Albert, R., and A-L. Barabási. 2001. 'Statistical Mechanics of Complex Networks.' doi:10.1103/ RevModPhys.74.47.

Albert, R., H. Jeong, and A-L. Barabási. 2000. 'Error and Attack Tolerance of Complex Networks.' Nature 406(6794): 378-382. doi:10.1038/35019019.

Baggio, J.A., S.B. BurnSilver, A. Arenas, J.S. Magdanz, G.P. Kofinas, and M. de Domenico. 2016. 'Multiplex Social Ecological Network Analysis Reveals How Social Changes Affect Community Robustness More Than Resource Depletion.' Proceedings of the National Academy of Sciences 113(48): 13708-13713. doi:10.1073/pnas.1604401113.

Baggio, J.A., and V. Hillis. 2018. 'Managing Ecological Disturbances: Learning and the Structure of Social-Ecological Networks.' Environmental Modelling and Software 109(August): 32-40. doi:10.1016/j. envsoft.2018.08.002. 
Baggio, J.A., K. Salau, M.A. Janssen, M.L. Schoon, and Ö. Bodin. 2011. 'Landscape Connectivity and Predator-Prey Population Dynamics.' Landscape Ecology 26(1): 33-45. doi:10.1007/ s10980-010-9493-y.

Barnes, M.L., Ö. Bodin, A. Guerrero, R. McAllister, S.M. Alexander, and G. Robins. 2017. 'Theorizing the Social Structural Foundations of Adaptation and Transformation in Social-Ecological Systems.' Social Science Research Network (January): 1-19. doi:10.5751/ES-09769-220416.

Barthélemy, M. 2011. 'Spatial Networks.' Physics Reports 499(1-3): 1-101. doi:10.1016/j.physrep. 2010.11.002.

Bodin, Ö., S.M. Alexander, J.A. Baggio, M.L. Barnes, R. Berardo, G.S. Cumming, L.E. Dee et al. 2019. 'Improving Network Approaches to the Study of Complex Social-Ecological Interdependencies.' Nature Sustainability 2(June): 551-559. www.nature.com/articles/s41893-019-0308-0.

Bodin, Ö., M.L. Barnes, R.R.J. McAllister, J.C. Rocha, and A.M. Guerrero. 2017. 'Social-Ecological Network Approaches in Interdisciplinary Research: A Response to Bohan et al. and Dee et al.' Trends in Ecology \& Evolution 32(8): 547-549. doi:10.1016/j.tree.2017.06.003.

Bodin, Ö., and B. Crona. 2008. 'Community-based Management of Natural Resources - Exploring the Role of Social Capital and Leadership in a Rural Fishing Community.' World Development 36(12): 2763-2779.

Bodin, Ö., and J. Norberg. 2007. 'A Network Approach for Analyzing Spatially Structured Populations in Fragmented Landscape.' Landscape Ecology 22(1): 31-44. doi:10.1007/s10980-006-9015-0.

Bodin, Ö., G. Robins, R.R. McAllister, A.M. Guerrero, B. Crona, M. Tengö, and M. Lubell. 2016. 'Theorizing Benefits and Constraints in Collaborative Environmental Governance: A Transdisciplinary Social-Ecological Network Approach for Empirical Investigations.' Ecology and Society 21(1): 40. doi:10.5751/ES-08368-210140.

Bodin, Ö., and M. Tengö. 2012. 'Disentangling Intangible Social-Ecological Systems.' Global Environmental Change 22(2): 430-439. doi:10.1016/j.gloenvcha.2012.01.005.

Borgatti, S.P. 2005. 'Centrality and Network Flow.' Social Networks 27(1): 55-71.

Borgatti, S.P., A. Mehra, D.J. Brass, and G. Labianca. 2009. 'Network Analysis in the Social Sciences.' Science 323(5916): 892-895. doi:10.1126/science.1165821.

Brummitt, C.D., G. Barnett, and R.M. d'Souza. 2015. 'Coupled Catastrophes: Sudden Shifts Cascade and Hop Among Interdependent Systems.' Journal of the Royal Society Interface 12(112). doi:10.1098/ rsif.2015.0712.

Caldarelli, G. 2007. Scale-Free Networks: Complex Webs in Nature and Technology. Oxford: Oxford University Press.

Costa, L. da F., O.N. Oliveira Jr, G. Travieso, F.A. Rodrigues, P.R. Villas Boas, L. Antiqueira, M. Palhares Viana, and L.E. Correa Rocha. 2011. 'Analyzing and Modeling Real-World Phenomena with Complex Networks: A Survey of Applications.' Advances in Physics 60(3): 329-412. doi:10 .1080/00018732.2011.572452.

Dakos, V., A. Quinlan, J.A. Baggio, E. Bennett, Ö. Bodin, and S. BurnSilver. 2015. 'Principle 2 - Manage Connectivity.' In Principles for Building Resilience, edited by R. Biggs, M. Schlüter, and M.L. Schoon, 80-104. Cambridge: Cambridge University Press. doi:10.1017/ CBO9781316014240.005.

De Domenico, M., C. Granell, M.A. Porter, and A. Arenas. 2016. 'The Physics of Spreading Processes in Multilayer Networks.' Nature Physics 12(10): 901-906. doi:10.1038/nphys3865.

De Domenico, M., A. Solé-Ribalta, E. Cozzo, M. Kivelä, Y. Moreno, M.A. Porter, S. Gómez, and A. Arenas. 2014. 'Mathematical Formulation of Multilayer Networks.' Physical Review X 3(4): 1-15. doi:10.1103/PhysRevX.3.041022.

Delgado-Serrano, M., E. Oteros-Rozas, P. Vanwildemeersch, C. Ortíz Guerrero, S. London, and R. Escalante. 2015. 'Local Perceptions on Social-Ecological Dynamics in Latin America in Three Community-based Natural Resource Management Systems.' Ecology and Society 20(4): 24. doi:10.5751/ES-07965-200424.

Dunne, J.A., R.J. Williams, and N.D. Martinez. 2002. 'Network Structure and Biodiversity Loss in Food Webs: Robustness Increases with Connectance.' Ecology Letters 5(4): 558-567.

Erdös, P., and A. Rényi. 1959. 'On Random Graphs.' Publicationes Mathematicae 6: 290-297. doi:10.2307/ 1999405.

Erdös, P., and A. Rényi. 1960. 'On the Evolution of Random Graphs.' Publications of the Mathematical Institute of the Hungarian Academy of Sciences 5: 17-61. 
Euler, L., and L. Euler. 1736. 'Solutio Problematis ad Geometrian Situs Pertinentis.' Comentarii Academiae Scientarum Petropolitanae. doi:002433.d/232323.

Frank, K.A., and K. Fahrbach. 1999. 'Organisational Culture as a Complex System: Balance and Information in Models of Influence and Selection.' Organization Science 10(3): 253-277.

Garlaschelli, D. 2004. Universality in Food Webs. European Physical Journal B 38(2): 277-285. doi:10.1140/epjb/e2004-00120-3.

Granell, C., S. Gomez, and A. Arenas. 2014. 'Competing Spreading Processes on Multiplex Networks: Awareness and Epidemics.' Physical Review E-Statistical, Nonlinear, and Soft Matter Physics 90(1): 1-7. doi:10.1103/PhysRevE.90.012808.

Guerrero, A.M., N.J. Bennett, K.A. Wilson, N. Carter, D. Gill, M. Mills, C.D. Ives et al. 2018. 'Achieving the Promise of Integration in Social-Ecological Research: A Review and Prospectus.' Ecology and Society 23(3): 38. doi:10.5751/ES-10232-230338.

Hamilton, M., A.P. Fischer, and A. Ager. 2019. 'A Social-Ecological Network Approach for Understanding Wildfire Risk Governance.' Global Environmental Change 54: 113-123.

Janssen, M.A., Ö. Bodin, J.M. Anderies, T. Elmqvist, H. Ernstson, R.R.J. McAllister, P. Olsson, and P. Ryan. 2006. 'Toward a Network Perspective of the Study of Resilience in Social-Ecological Systems.' Ecology and Society 11(1): 15.

Keitt, T., D. Urban, and B. Milne 1997. 'Detecting Critical Scales in Fragmented Landscapes.' Conservation Ecology 1(1): 4.

Kivelä, M., A. Arenas, M. Barthélemy, J.P. Gleeson, Y. Moreno, and M.A. Porter. 2014. 'Multilayer Networks.' ArXiv 2: 203-271. doi:arXiv:1309.7233.

Maciejewski, K., and G. Cumming. 2015. 'The Relevance of Socio-economic Interactions for the Resilience of Protected Area Networks.' Ecosphere 6(9): 1-14.

Markowetz, F. 2010. 'How to Understand the Cell by Breaking It: Network Analysis of Gene Perturbation Screens.' PLoS Computational Biology 6(2): e1000655.

Minor, E.S., and D.L. Urban. 2007. 'Graph Theory as a Proxy for Spatially Explicit Population Models in Conservation Planning.' Ecological Applications 17(6): 1771-1782. doi:10.1890/06-1073.1.

Moreno, J.L. 1934. 'Who Shall Survive: A New Approach to the Problem of Human Interrelations.' Nervous and Mental Diseases Monographs 58. https://archive.org/details/whoshallsurviven00jlmo

Nicosia, V., R. Criado, M. Romance, G. Russo, and V. Latora. 2012. 'Controlling Centrality in Complex Networks.' Scientific Reports 2: 1-7. doi:10.1038/srep00218.

Poledna, S., J.L. Molina-Borboa, S. Martinez-Jaramillo, M. van der Leij, and S. Thurner. 2015. 'The Multi-layer Network Nature of Systemic Risk and its Implications for the Costs of Financial Crises.' Journal of Financial Stability 20: 70-81. doi:10.2307/2597748.

Sayles, J.S., and J.A. Baggio. 2017a. 'Social-Ecological Network Analysis of Scale Mismatches in Estuary Watershed Restoration.' Proceedings of the National Academy of Sciences 114(10): 201604405. doi:10.1073/pnas.1604405114.

Sayles, J.S., and J.A. Baggio. 2017b. 'Who Collaborates and Why: Assessment and Diagnostic of Governance Network Integration for Salmon Restoration in Puget Sound, USA.' Journal of Environmental Management 186: 64-78. doi:10.1016/j.jenvman.2016.09.085.

Sayles, J., M.M. Garcia, M. Hamilton, S. Alexander, J. Baggio, A.P. Fischer, and J. Pittman. 2019. 'Social-Ecological Network Analysis for Sustainability Sciences: A Systematic Review and Innovative Research Agenda for the Future.' Environmental Research Letters, 1-5. doi:10.1088/1748-9326/ab2619.

Urban, D., and T. Keitt. 2001. 'Landscape Connectivity: A Graph-theoretic Perspective.' Ecology 82(5): 1205-1218.

Wang, P., K. Sharpe, G.L. Robins, and P.E. Pattison. 2009. 'Exponential Random Graph (P^) Models for Affiliation Networks.' Social Networks 31(1): 12-25. doi:10.1016/j.socnet.2008.08.002.

Watts, D.J., and S.H. Strogatz. 1998. 'Collective Dynamics of "Small-World" Networks.' Nature 393(6684): 440-442. doi:10.1038/30918. 